\title{
Corrosion Behavior and Failure Mechanism of Prestressed Rock Bolts (Cables) in the Underground Coal Mine
}

\author{
Qiong Wang $\mathbb{D}^{1}$ Fengnian Wang $\mathbb{D}^{2}$, Aiwu Ren $\mathbb{D}^{3},{ }^{3}$ Rui Peng $\mathbb{D},{ }^{1}$ and Jian Li $\mathbb{D}^{1}$ \\ ${ }^{1}$ Department of Emergency Technology and Management, North China Institute of Science \& Technology, Beijing 101601, China \\ ${ }^{2}$ School of Mechanics and Civil Engineering, China University of Mining \& Technology, Beijing 100083, China \\ ${ }^{3}$ China Renewable Energy Engineering Institute, Beijing 100120, China
}

Correspondence should be addressed to Fengnian Wang; wangfn_bj@163.com

Received 31 October 2020; Revised 27 January 2021; Accepted 22 February 2021; Published 2 March 2021

Academic Editor: Luís C. Neves

Copyright ( 2021 Qiong Wang et al. This is an open access article distributed under the Creative Commons Attribution License, which permits unrestricted use, distribution, and reproduction in any medium, provided the original work is properly cited.

Premature failure of rock bolts (cables) due to stress corrosion cracking (SCC) is a phenomenon that has been reported to occur in the underground environment. In the 1990s, many failure accidents of bolts which occurred in the United Kingdom were caused by SCC [1]. In this study, the corrosion behavior and failure mechanism of rock bolt (cable) samples obtained from the underground coal mine were examined and discussed. Macroscopic observation and weight loss tests were carried out for the bolts' corrosion characteristics without failure. The results show that the bolts with short service time (1.5-2 yrs) underwent uniform corrosion. However, bolts with longer service time (3-8 yrs) experienced different pitting corrosion degrees. The corroding degree of different parts of bolt samples shows the following decreasing trend: bolt head $>$ bolt end $>$ free section. The absolute corrosion degree increased with the service time, while the corrosion rate was the highest in the early stage and dropped down in the later stage. At the same time, the macro- and micromethods were used to analyse the failure mechanism in the broken cable sample. Failure of one cable sample with a medium service life (6 yrs) was found to be controlled by the SCC. It was induced by long-term action of $\mathrm{O}, \mathrm{Cl}$, and $\mathrm{S}$ in the surrounding rock environment and resulted in pitting corrosion. The pitting corrosion reduced the outer diameter of the rock cable and its bearing capacity, leading to the final fracture.

\section{Introduction}

The prestressed rock bolt (cable) technology has been used since $1934[1,2]$. It was widely applied in geotechnical engineering for its advantages, such as light structure and low cost [3-6]. However, since prestressed bolts (cables) are materials reinforced with steel bars or strands, their durability is strongly affected by the long-term action of the surrounding rock environment. Thus, several researchers have collected and analysed some rock bolt (cable) failure cases [7-9]. Chandra and Jack [10] carried out the study of corrosion characteristics and mechanism of different rock cables under the influence of nuclear waste in the Yucca Mountain geological environment. Erwina [11] studied the influence of environmental factors on the stress corrosion failure of the prestressed bolt through the indoor test.
In China, Zheng et al. [12] carried out experimental research on the influence of environmental factors on the bolt's mechanical properties. Zhao et al. [13] studied the factors affecting the durability of the bolt under the stress and environmental corrosion condition. Li [14] quantitatively described the influence of the $\mathrm{pH}$ value, time, stress level, and other factors on the corrosion amount per unit length of the specimen through the indoor accelerated corrosion test. $\mathrm{Li}$ [15] analysed the influence characteristics of chloride ion concentration, time, $\mathrm{pH}$ value, and other factors on the corrosion of the cables and the mutual coupling relationship between different influencing factors through the indoor test. Zeng et al. [16] studied the strength index and apparent characteristics of the rock cable under the corrosion environment; Zhang et al. [17] observed the corrosion damage morphology of the prestressed rock cable under different times, established the relationship between 
the indicators such as the corrosion pit area (depth) and the time, and analysed the surface damage evolution law of the stress corrosion. Aziz et al. [18] conducted a stress corrosion test for 3.5 years on four rock bolts and found that the strength of the four rock bolts decreased $21 \%$ to $39 \%$. Wu et al. [19] conducted a stress corrosion cracking test on the bolts by simulating the stress state and local chemical environment. The results showed that the stress intensity had a significant influence on the corrosion damage of the specimen.

At present, most of the research studies on the durability of the rock bolt (cable) were limited to the indoor test of the simulated corrosion environment, which was quite different from the actual working environment of the rock bolt (cable). In this paper, the bolt samples obtained from an underground coal mine were experimentally investigated to study the corrosion characteristics through the macro-observation and weight loss test. Meanwhile, macro- and micromethods were adopted to analyse the failure mechanism of the rock cable.

\section{Examination of Rock Bolts (Cables) Obtained from the Underground Coal Mine}

2.1. Sampling Condition. The samples were taken from Qishan Coal Mine in Xuzhou, China, which was put into operation in December 1959. The influencing environmental factors such as temperature, $\mathrm{pH}$, and harmful ions were tested. It was found that the surrounding rock environment of the bolts (cables) is nearly the same at the same horizontal stratum, which provides the possibility to study the corrosion behavior of the rock bolts with different service years in the underground coal mine. Synthetically considering the service time and the difficulty of on-site sampling, six full-length adhesive samples were drilled out in the $-700 \mathrm{~m}$ East Wing return airway. Among them, five samples were undamaged rock bolts, and one was a failed rock cable.

Figure 1 shows the fielding sampling diagram. After the bolt (cable) samples were drilled out, they were immediately packed and sealed with the plastic wrap to avoid accelerated corrosion. The samples obtained from the underground coal mine are shown in Figure 2, which were numbered as S-1, S-2, S-3, S-4, S-5, and S-6, respectively. The details of bolt (cable) samples are listed in Table 1.

\section{Corrosion Behavior of Bolt Samples}

The corrosion degree of undamaged bolt samples was analysed. Firstly, the appendages on the sample surface, such as soil and resin, were decontaminated by the ultrasonic vibration. Then, the weight loss was measured by acid pickling on $2 \mathrm{~cm}$-long samples, which were taken from the bolt head, free section, and anchorage section, respectively. Figure 3 shows the schematic diagram of bolt samples before and after derusting. The mass loss can directly and quantitatively characterize the bolt's corrosion degree, which is calculated by equation (1), while the bolt's corrosion rate is calculated via equation (2):

$$
\begin{aligned}
& \Delta W=\frac{w_{0}-w_{1}}{A_{0}} \pm \Delta W_{U}, \\
& v_{\text {corr }}=\frac{\Delta W}{t},
\end{aligned}
$$

where $\Delta W$ is the weight loss per unit area of the bolt; $w_{0}$ is the mass before derusting of the bolt; $w_{1}$ is the mass after derusting; $A_{0}$ is the surface area of the bolt; $\Delta W_{U}$ is the weight loss per unit area of the original stainless bolt after pickling, and $\Delta W_{U}=W_{U 0}-W_{U 1} ; W_{U 0}$ is the mass per unit area of the original stainless bolt before pickling; $W_{U 1}$ is the mass per unit area after pickling; $v_{\text {corr }}$ is the corrosion rate of the bolt; and $t$ is the service time of the bolt.

As shown by the bolt samples' appearance, all samples have slight corrosion, which can be divided into uniform corrosion and local pit corrosion. S-1 and S-2 are characterized by uniform corrosion, and pit corrosion occurs in different parts of S-3, S-4, and S-5. The number of corrosion spots on the surface of each sample increases with service time. For example, a large area of corrosion spots can be found on the S- 5 bolt's surface, which has been used for eight years, and the depth of some pits reaches $0.18 \mathrm{~mm}$.

Figure 4 shows the time-mass loss relation diagram of different parts of the bolt. As shown in Figure 4, with an increase in service time, the corrosion degree of different bolt parts increases year by year. The rule of the anchor head characterizes the corrosion amount of different parts $>$ anchor end $>$ free section. This is because the anchor head has been exposed to the air for a long time, and $\mathrm{O}_{2}$ in the air accelerates the corrosion of the anchor head, while other parts are wrapped by concrete mortar for a long time with less contact with corrosive media, so the corrosion is relatively light in degree.

Figure 5 shows the variation curve of the corrosion rate of different parts of the bolt. It can be seen that each part of the bolt's corrosion rate increases rapidly in the early stage and slows down in the later stage. The reason is that, with the increase of service time, the corrosion on the surface of the bolt is accumulated, which avoids the large area of contact between the bolt body and external corrosion factors, thus reducing the growth rate of bolt corrosion.

\section{Microstructure Examination on the Fracture Surface of a Failed Rock Cable}

4.1. Macroscopic Analysis of the Sample Fracture. The failure analysis of anchor cable sample S-6 in use for six years in Qishan Coal Mine was conducted. Figure 6 shows the overall morphology of S-6. The anchor cable has a brown surface and consists of seven steel strands. The corrosion morphology of each area of the broken anchor cable sample is shown in Figure 7. The macroanalysis results show that the whole anchor cable is characterized by uniform oxidation corrosion (Figure 7(a)). Pit corrosion is found in some steel strand areas in the region from about $900 \mathrm{~mm}$ away from the anchorage to the fracture, as shown by the arrow in Figure 7(b). However, near the fracture (about $1200 \mathrm{~mm}$ away from the anchorage), the number and degree of pit corrosion are relatively serious, and some places even have 


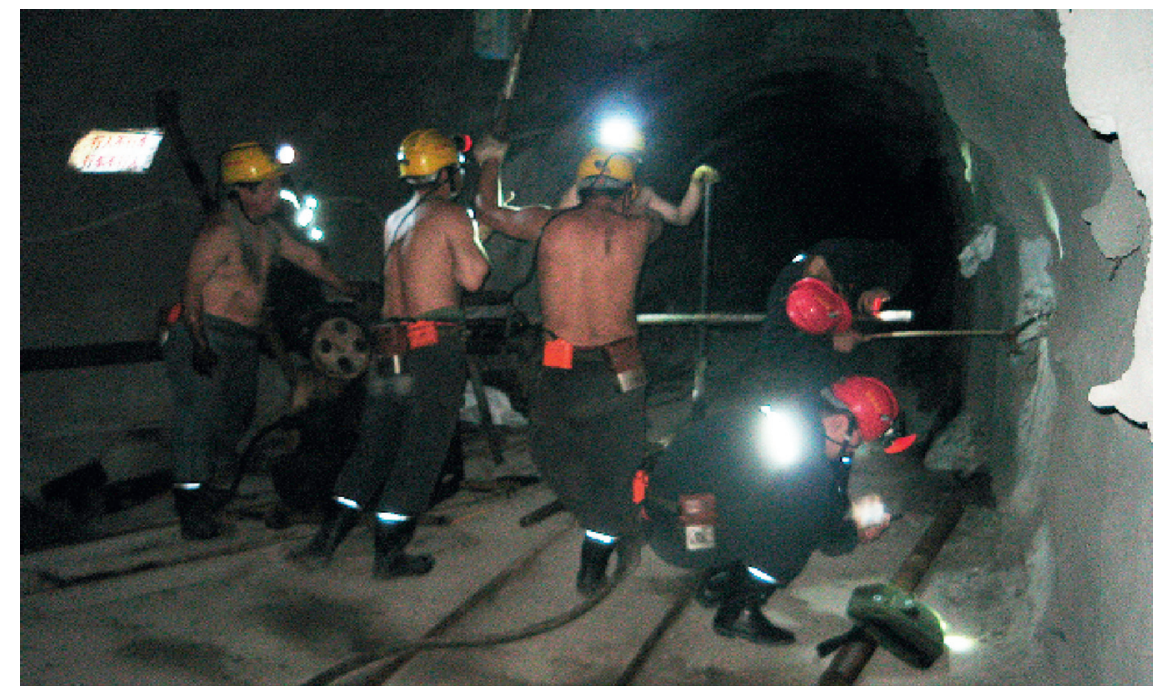

(a)

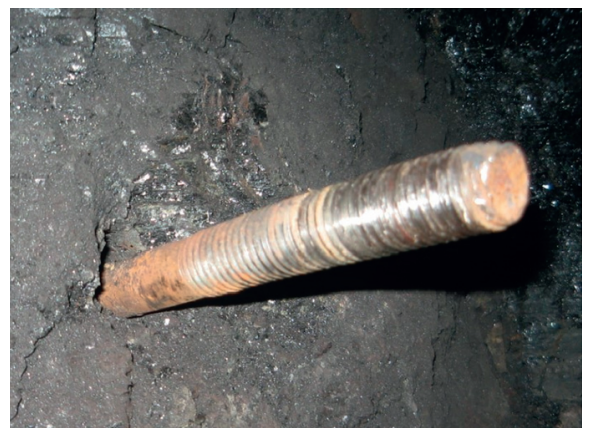

(b)

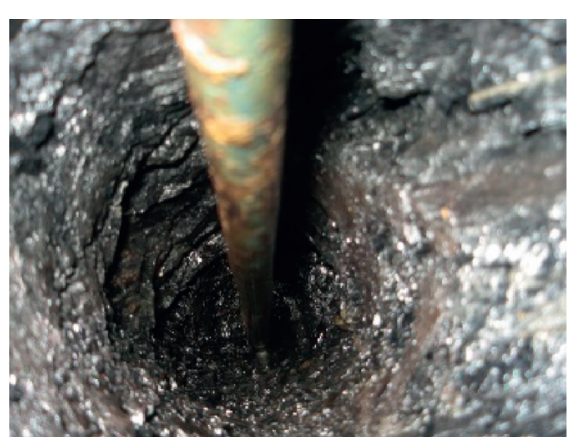

(c)

FIgURE 1: Field sampling diagram. (a) On-site drilling for bolt samples. (b) The bolt before drilling. (c) The bolt after drilling.

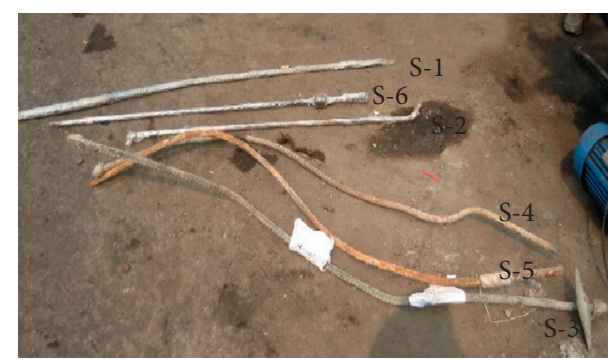

Figure 2: Bolt (cable) samples drilled from the underground coal mine.

spalling (Figure 7(c)). As shown in Figure 7(c), the steel strand's length at the breaking point of the anchor cable is different. It is an inclined fracture formed under tensile stress with a certain angle to the axial direction, and the longitudinal length of the fracture is about $25 \mathrm{~mm}$. There is no obvious necking before fracture of these steel wires, and it can be observed that the steel strands crack from the outer surface with more serious oxidation and corrosion.

\section{Microscopic Analysis of Corrosion Products of the Sample Fracture}

5.1. Analysis of Corrosion Products on the Fracture Surface and Its Vicinity. The macroscopic and microscopic fracture morphology analyses were carried out after the position marked with white words was cleaned in Figure 7. The microscopic corrosion product morphology and EDS energy spectrum composition analysis on the fracture surface are shown in Figure 8. The fracture surface's microscopic analysis results show that the fracture surface is mainly covered by iron oxide, and sulfur corrosion products are detected in the local area.

The morphology of microscopic corrosion products on the fracture edge surface and EDS energy spectrum composition analysis are shown in Figure 9. The results show that the corrosion products are mainly in fluffy needle and ball shape. The corrosion products' main components as detected are $\mathrm{Fe}, \mathrm{O}, \mathrm{Cl}, \mathrm{S}, \mathrm{Si}, \mathrm{Mn}, \mathrm{Cr}$, etc. The content of element $\mathrm{Cl}$ in the corrosion products is as high as $4.4 \%$, and the mass content of element $\mathrm{S}$ is $0.6 \%$. 
TABLe 1: The details of bolt (cable) samples.

\begin{tabular}{|c|c|c|c|c|c|c|c|c|c|}
\hline \multirow[b]{2}{*}{ Sample } & \multirow{2}{*}{$\begin{array}{l}\text { Bolt } \\
\text { diameter } \\
(\mathrm{mm})\end{array}$} & \multirow{2}{*}{$\begin{array}{l}\text { Service } \\
\text { period } \\
\text { (year) }\end{array}$} & \multirow{2}{*}{$\begin{array}{c}\text { Residual } \\
\text { prestress } \\
(\%)\end{array}$} & \multicolumn{5}{|c|}{ Working environment } & \multirow{2}{*}{$\begin{array}{c}\text { Sample morphological } \\
\text { description }\end{array}$} \\
\hline & & & & $\begin{array}{l}\text { Surrounding } \\
\text { rock }\end{array}$ & Temperature & Humidity & $\begin{array}{c}\text { Seepage } \\
\text { water pH }\end{array}$ & $\begin{array}{l}\text { Harmful } \\
\text { ions }\end{array}$ & \\
\hline S-1 & 20 & 1.5 & $\geq 70$ & Coal & 25.2 & 93.6 & 7.1 & $\mathrm{SO}_{4}{ }^{2-}, \mathrm{Cl}^{-}$ & $\begin{array}{l}\text { Greenish brown and } \\
\text { slightly uniform } \\
\text { corroded, no failure }\end{array}$ \\
\hline S-2 & 20 & 2.0 & $\geq 70$ & Coal & 24.9 & 90.8 & 7.4 & $\mathrm{SO}_{4}{ }^{2-}, \mathrm{Cl}^{-}$ & $\begin{array}{l}\text { Greenish brown and } \\
\text { slightly uniform } \\
\text { corroded, no failure }\end{array}$ \\
\hline S-3 & 20 & 3.0 & $\geq 70$ & Coal & 25.6 & 91.5 & 7.5 & $\mathrm{SO}_{4}^{2-}, \mathrm{Cl}^{-}$ & $\begin{array}{l}\text { Greenish brown and } \\
\text { slightly pitting } \\
\text { corroded, no failure }\end{array}$ \\
\hline S-4 & 20 & 5.0 & $\geq 70$ & Coal & 24.8 & 93.2 & 7.2 & $\mathrm{SO}_{4}{ }^{2-}, \mathrm{Cl}^{-}$ & $\begin{array}{l}\text { Reddish brown and } \\
\text { severe pitting } \\
\text { corroded, no failure }\end{array}$ \\
\hline S-5 & 20 & 8.0 & $\geq 70$ & Coal & 25.2 & 92.9 & 7.4 & $\mathrm{SO}_{4}{ }^{2-}, \mathrm{Cl}^{-}$ & $\begin{array}{l}\text { Reddish brown and } \\
\text { severe pitting } \\
\text { corroded, no failure }\end{array}$ \\
\hline S-6 & 16 & 6.0 & $\geq 70$ & Coal & 24.9 & 93.3 & 7.6 & $\mathrm{SO}_{4}{ }^{2-}, \mathrm{Cl}^{-}$ & $\begin{array}{l}\text { Reddish brown and } \\
\text { severe pitting } \\
\text { corroded, failure }\end{array}$ \\
\hline
\end{tabular}

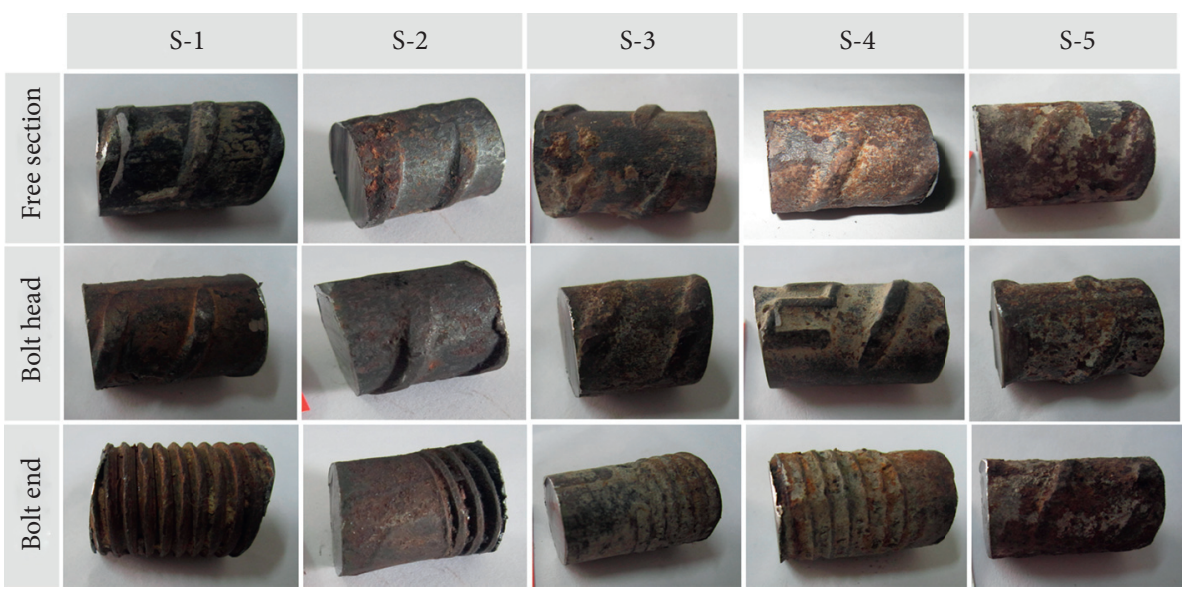

(a)

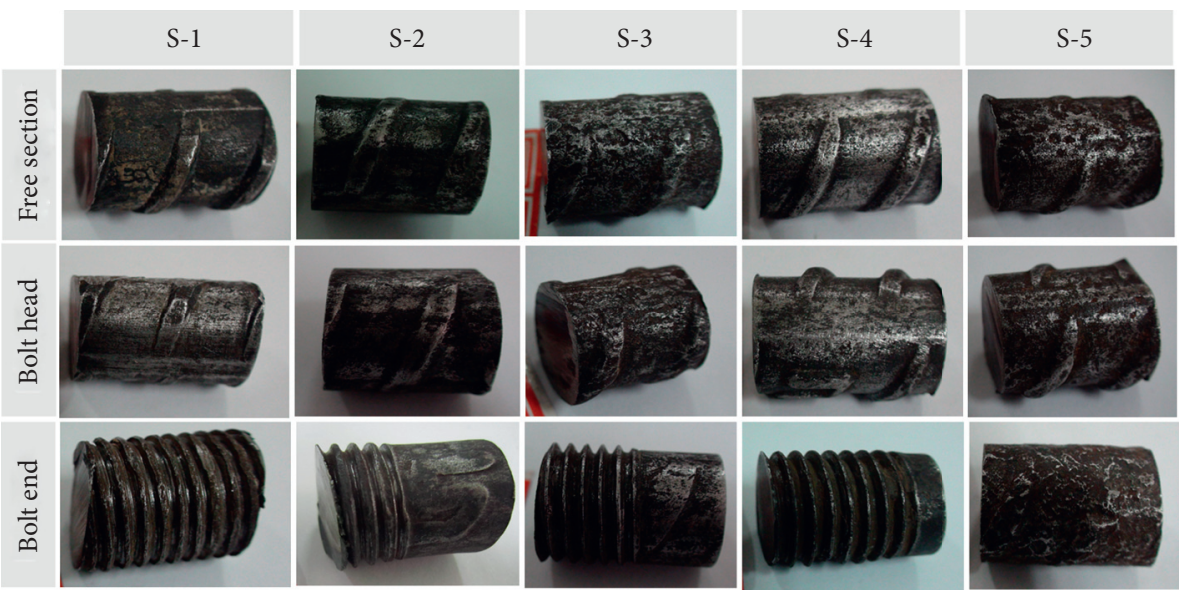

(b)

FIgURE 3: Comparison of the bolt sample (a) before derusting and (b) after derusting. 


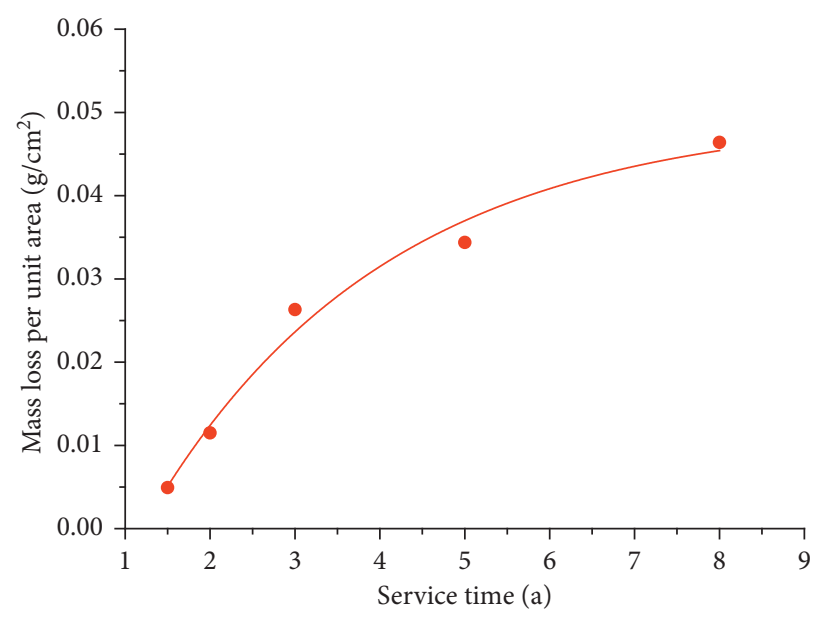

(a)

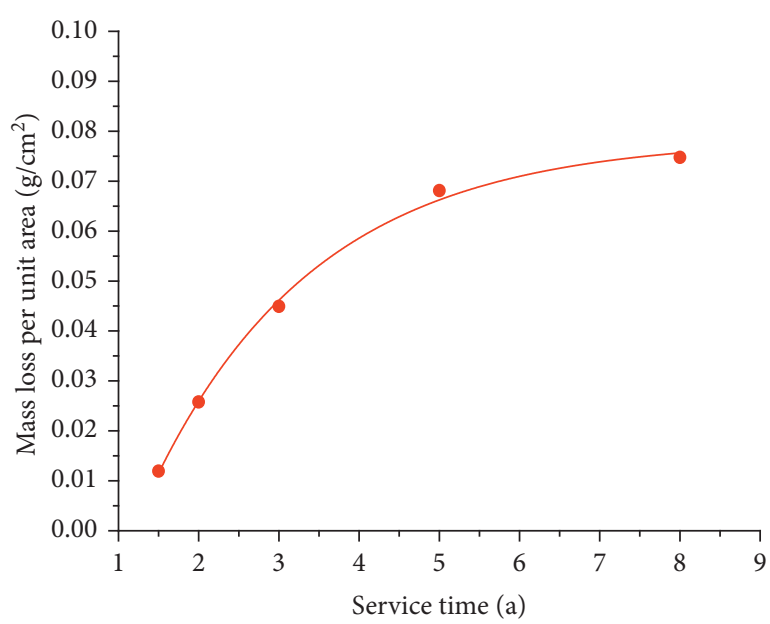

(b)

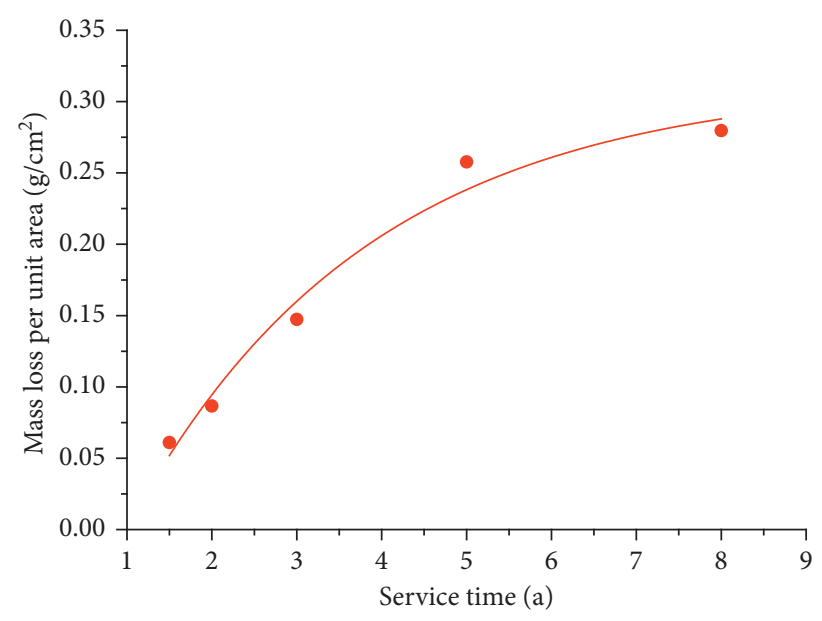

(c)

Figure 4: Time-mass loss relationship of different parts of the bolt. (a) Free section. (b) Anchor end. (c) Anchor head.

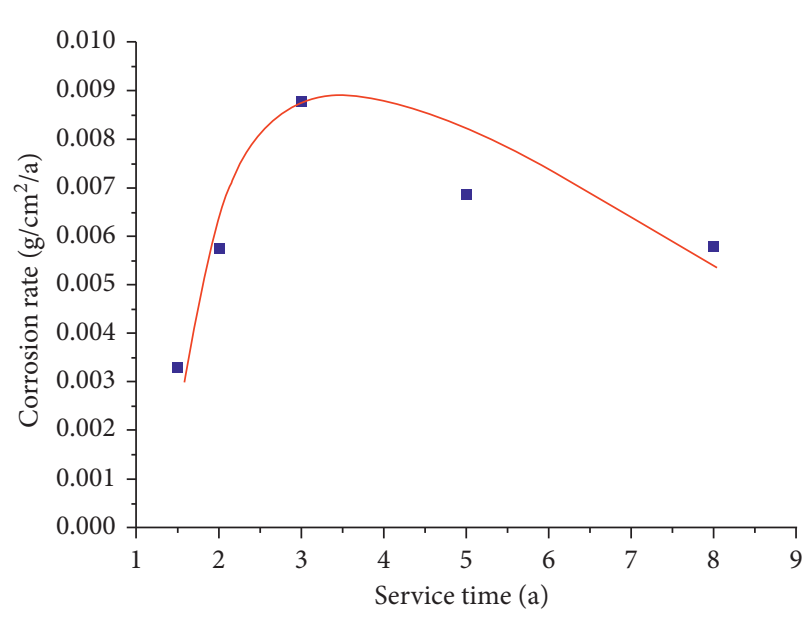

(a)

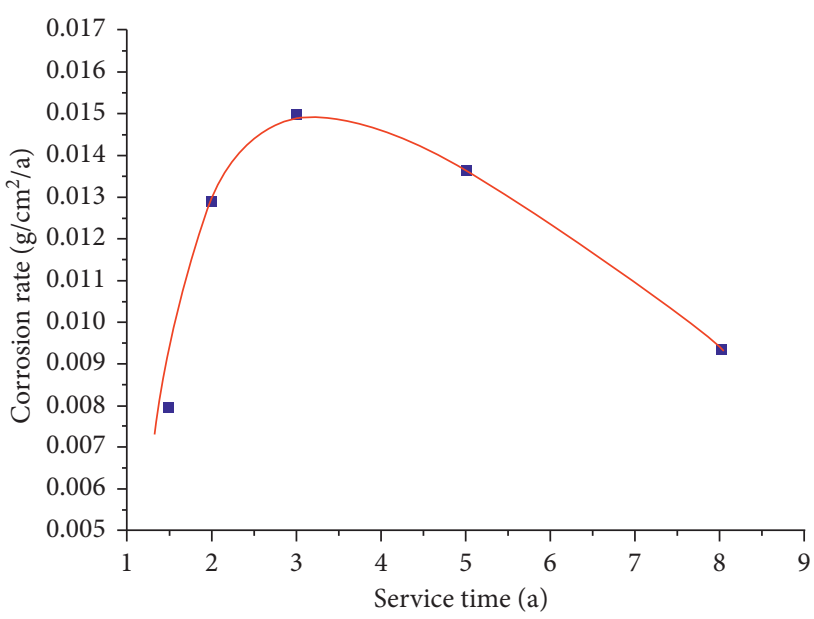

(b)

Figure 5: Continued. 


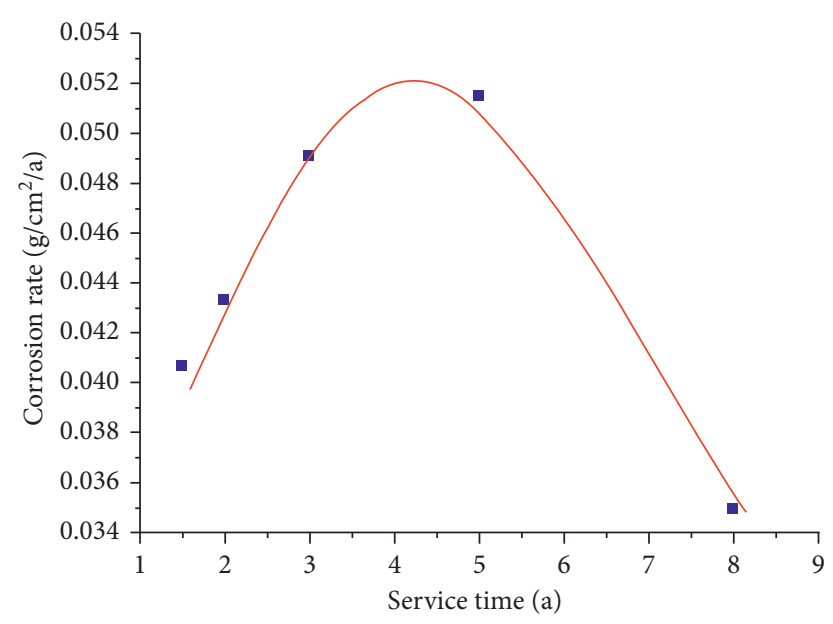

(c)

Figure 5: Variation of corrosion rate in different parts of the bolt. (a) Free section. (b) Anchor end. (c) Anchor head.

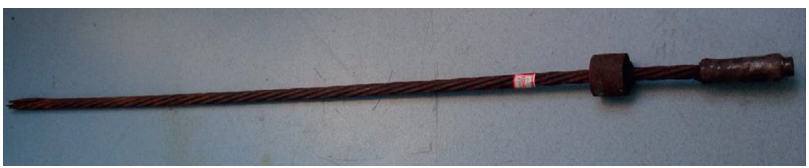

(a)

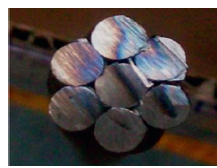

(b)

Figure 6: Morphology of the broken anchor cable: (a) longitudinal morphology; (b) transverse section morphology.

\subsection{Analysis of Corrosion Products on the Fracture and Steel} Strand Profile. The transverse section's metallographic samples were taken from the pit corrosion area about $900 \mathrm{~mm}$ away from the anchorage near the nonfracture area. After sample grinding and polishing, the morphology was observed by using the scanning electron microscope, and the EDS energy spectrum composition was analysed. Figure 10 shows the low-speed fracture of the steel wire, while Figures 11(a)11(c) show the microscopic morphology and composition analysis of corrosion products of the area near the matrix, near the surface, and inside the matrix of the reinforcement in the area with pit corrosion. Figure 12 shows the microscopic morphology and composition analysis of corrosion products near the matrix, near the surface, and inside the reinforcement matrix in the area without pit corrosion. The analysis results show that the depth of some pits reaches $0.9 \mathrm{~mm}$. In the pit corrosion area, the corrosion products containing $\mathrm{O}$, $\mathrm{Cl}$, and $\mathrm{S}$ or $\mathrm{O}$ and $\mathrm{S}$ are found near the steel strand matrix and the surface; in the area without pit corrosion, the corrosion products containing $\mathrm{O}$ are mainly found near the steel strand matrix and the surface.

\section{Sample Failure Mechanism}

As known from the macroscopic and microscopic analysis of the samples, the failure samples are not characterized by obvious plastic deformation or necking, indicating that the sample's failure mode is a brittle failure. The sample's fracture path profile can be divided into three stages, as shown in Figure 13. There is a shallow crack perpendicular to the applied load in the fracture initiation area (Figure 13(a)). Then, the crack deflects and propagates along the longitudinal direction in the second stage (Figure 13(b)). Lastly, the sample was suddenly fractured with a higher deviation angle in the third stage (Figure 13(c)). This type of failure has also been observed in other research results [20-22], which is considered to be a typical feature of SCC. To sum up, the failed samples have been in the $\mathrm{O}, \mathrm{Cl}$, and $\mathrm{S}$ surrounding rock environment for a long time, which results in pit corrosion, causes the corrosion and spalling of the surface material of the steel strand, reduces the outer diameter of the anchor cable and its bearing capacity, and leads to one-time SCC fracture of the anchor cable. 


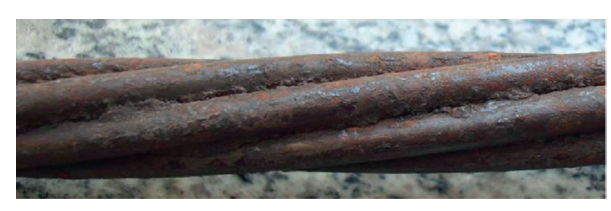

(a)

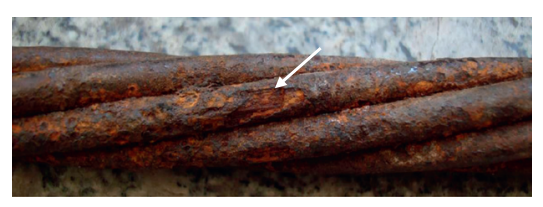

(b)

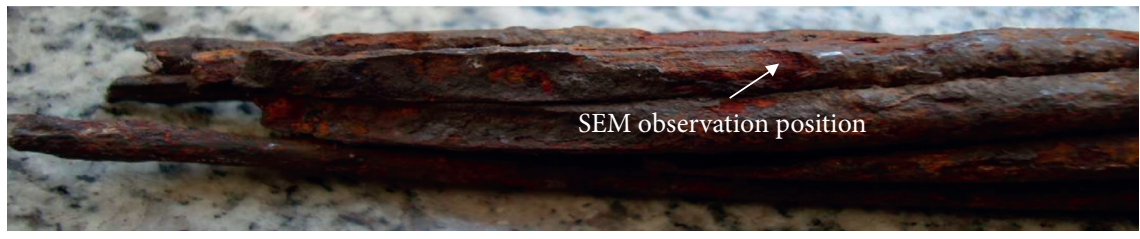

(c)

Figure 7: Macrofracture corrosion morphology of the anchor cable: (a) the steel strand near the anchorage; (b) the steel strand near the anchorage, about $900 \mathrm{~mm}$ away from the anchorage; (c) fracture position.
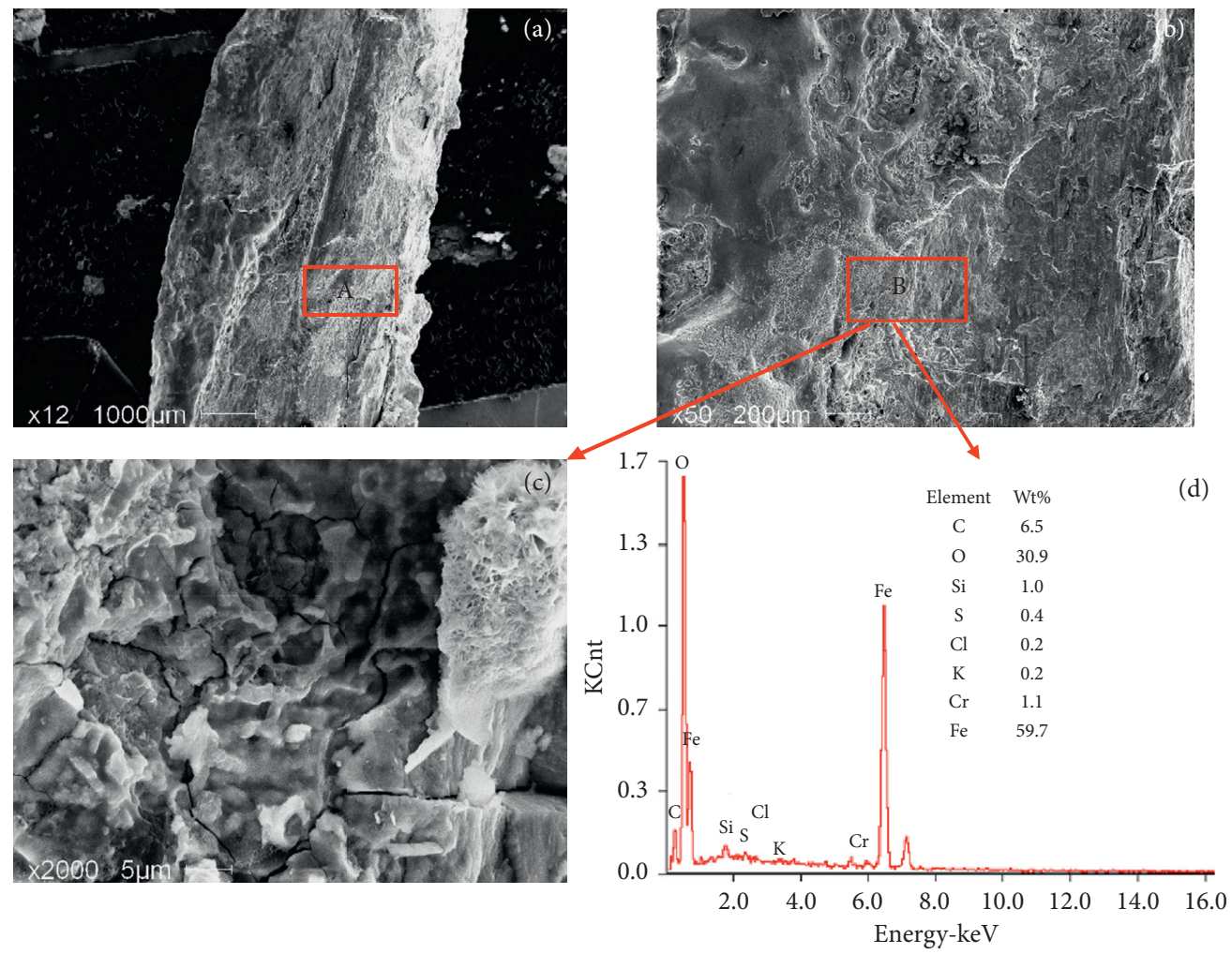

FIGURE 8: Morphology and EDS analysis of fracture surface corrosion products: (a) with 12 times magnification; (b) point A with 50 times magnification; (c) point B with 2000 times magnification; (d) EDS analysis. 


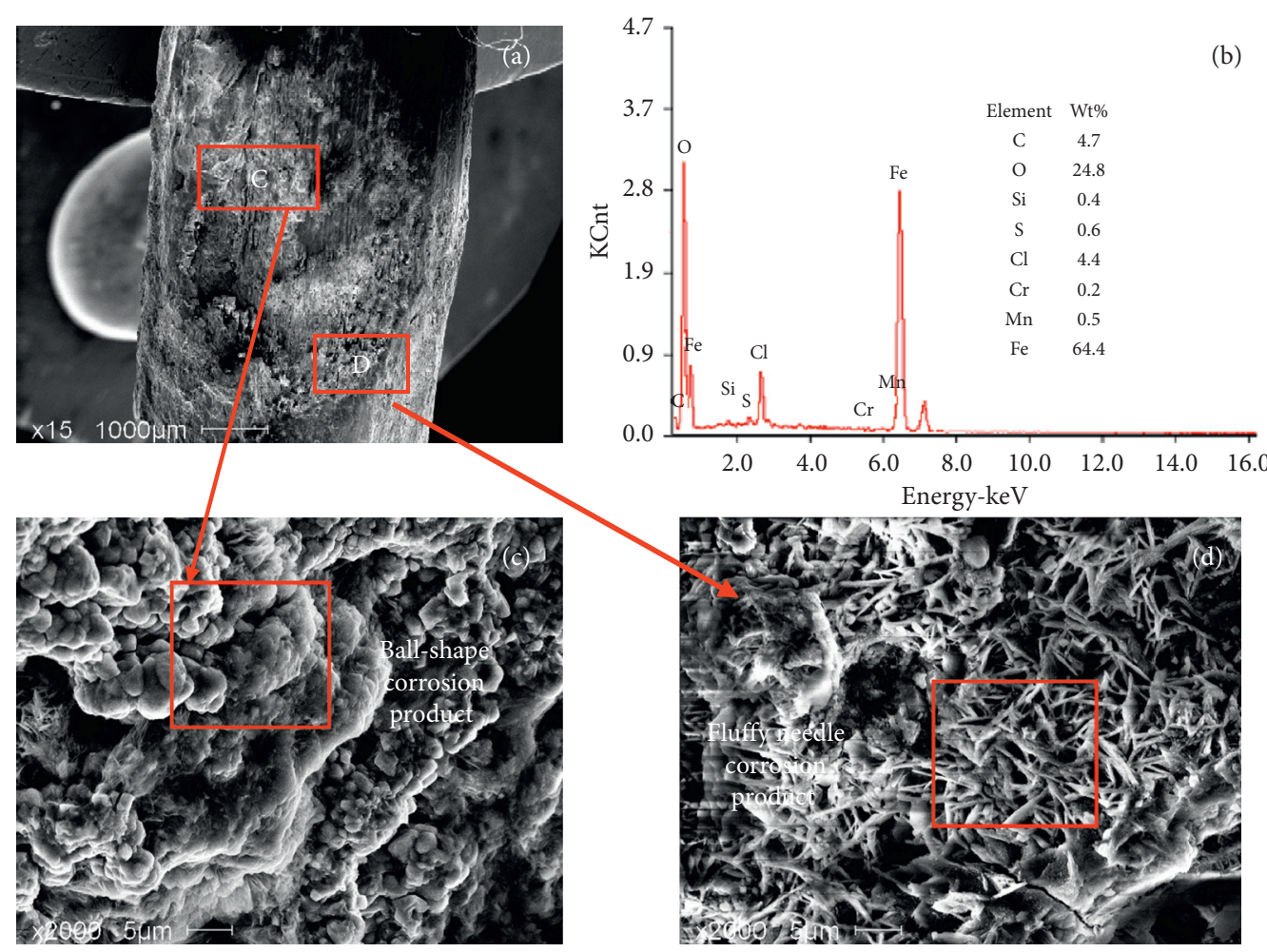

Figure 9: Morphology and EDS analysis of surface corrosion products near the fracture: (a) with 15 times magnification; (b) EDS analysis; (c) point C with 2000 times magnification; (d) point D with 2000 times magnification.

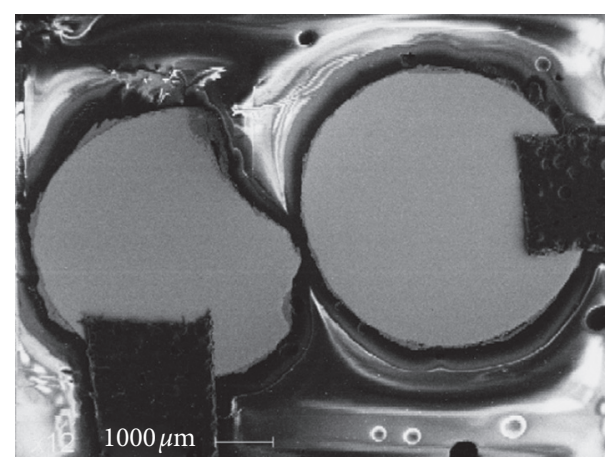

FIGURE 10: Low-power images of metallographic samples of the transverse section of the steel strand with and without pit corrosion. 

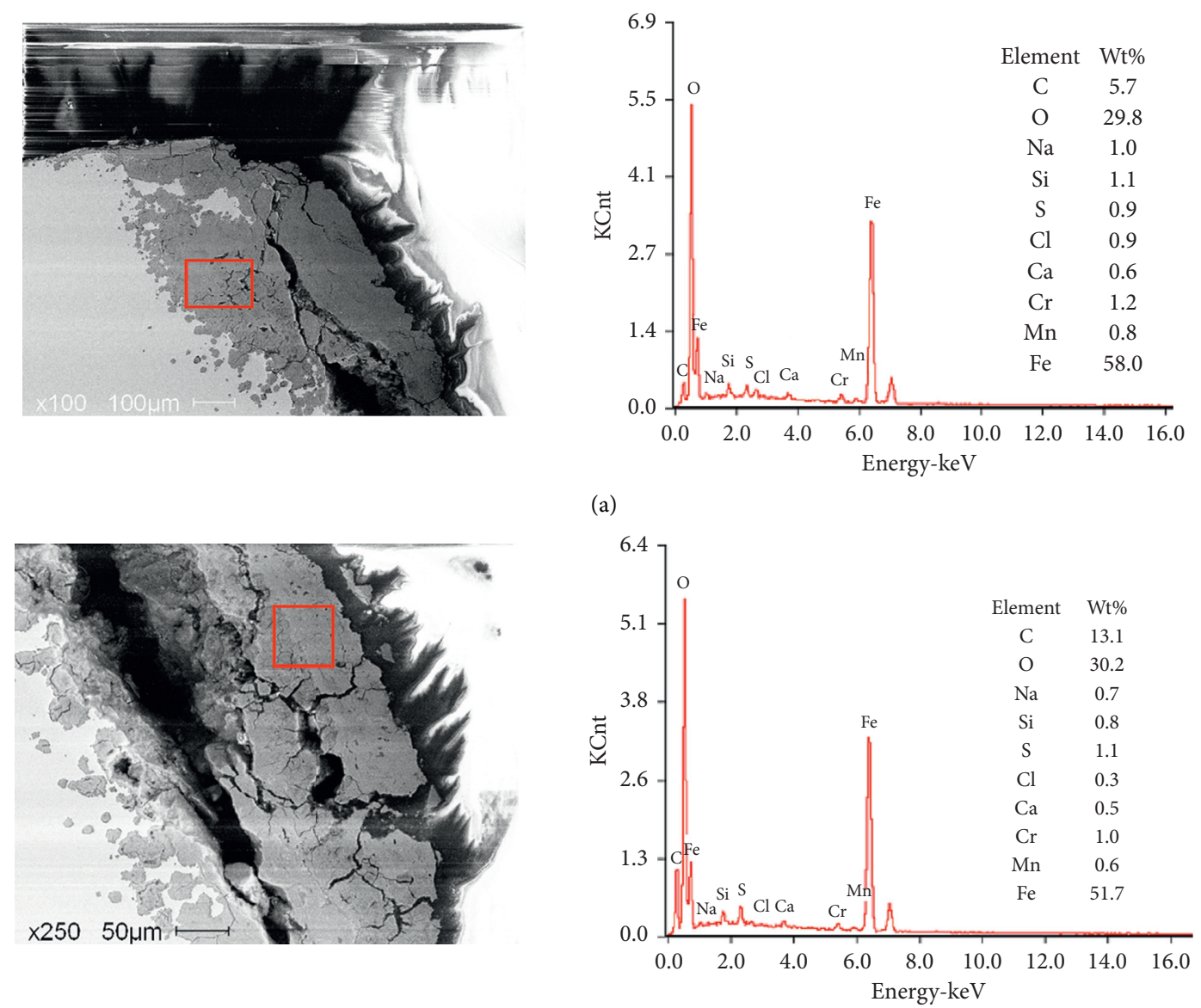

(b)
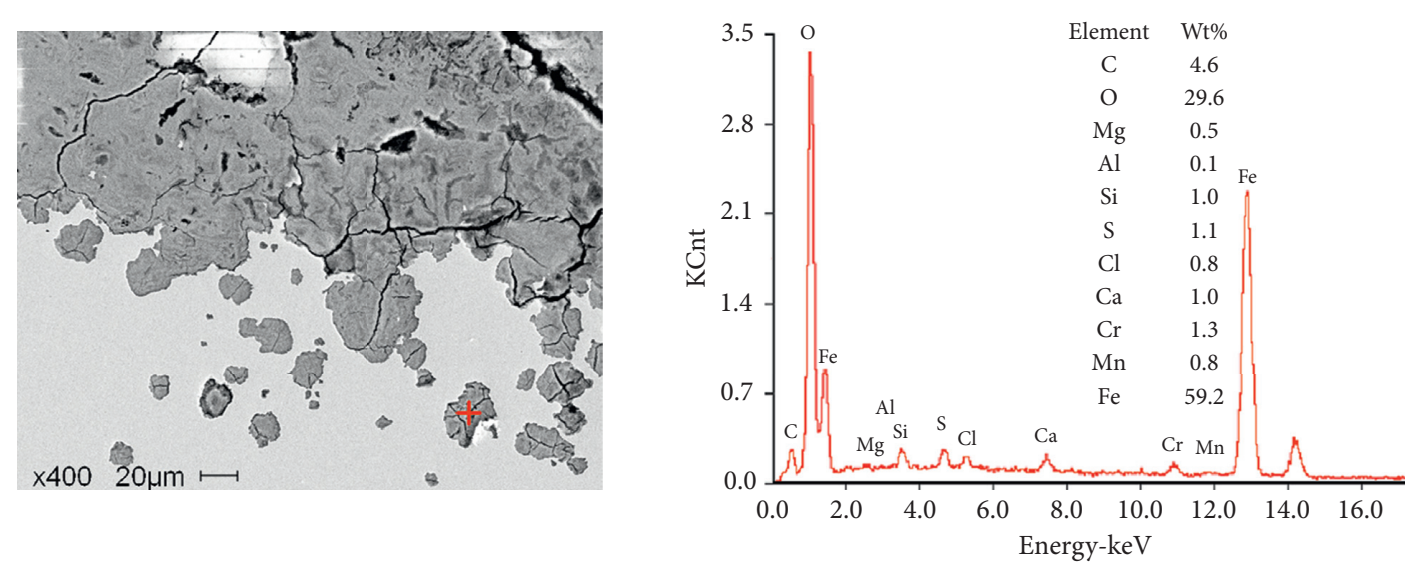

(c)

FIGURE 11: EDS energy spectrum analysis of corrosion products in pits of metallographic samples of transverse section. (a) Composition of corrosion products near the matrix in the pit corrosion area. (b) Composition of near-surface corrosion products in the pit corrosion area. (c) Composition of point corrosion products in the matrix. 


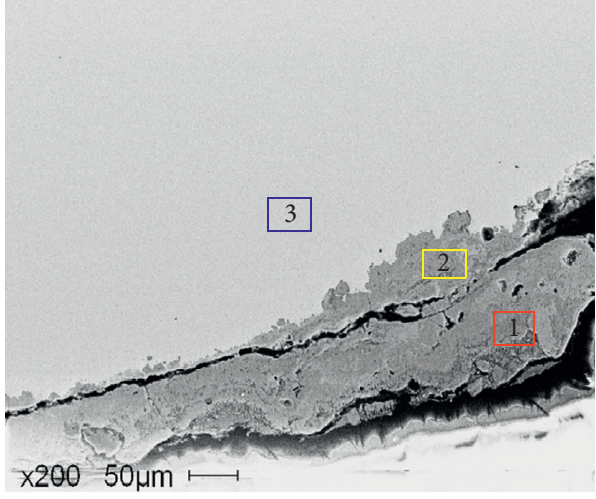

(a)

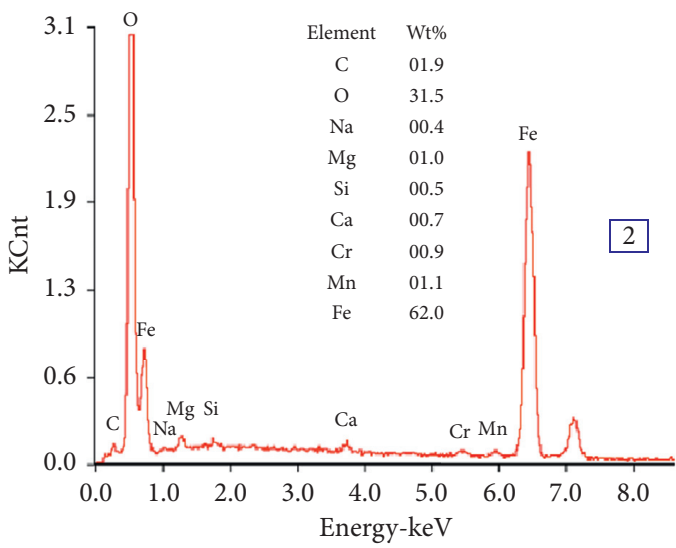

(c)

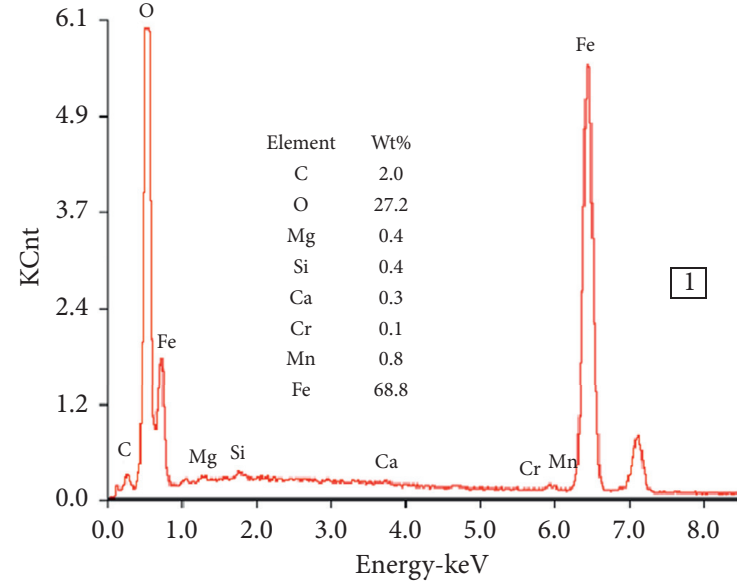

(b)

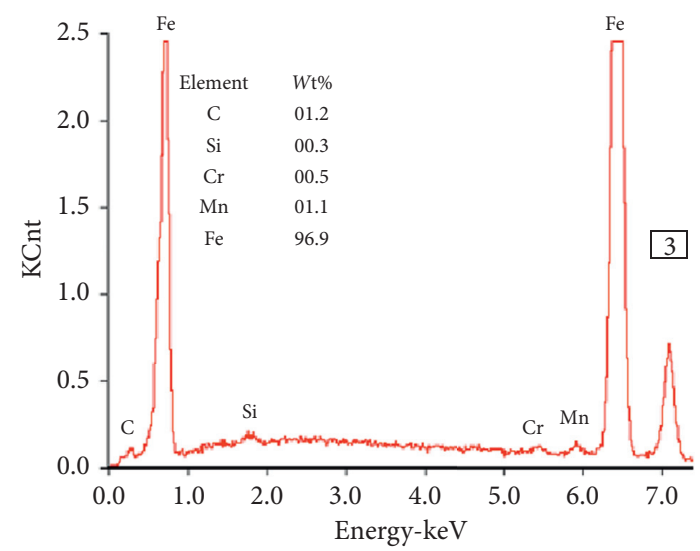

(d)

FIGURE 12: EDS energy spectrum analysis of corrosion products in the area without pits of transverse section. (a) Corrosion morphology. (b) Composition of near-surface corrosion products. (c) Composition of corrosion products near the matrix. (d) Composition of corrosion products in the matrix.

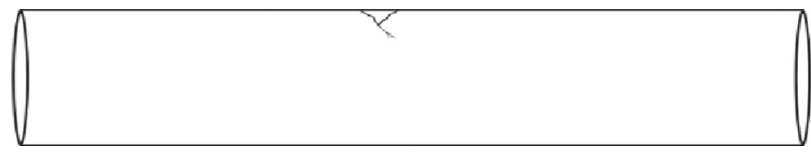

(a)

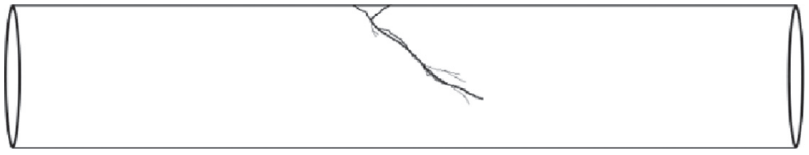

(b)

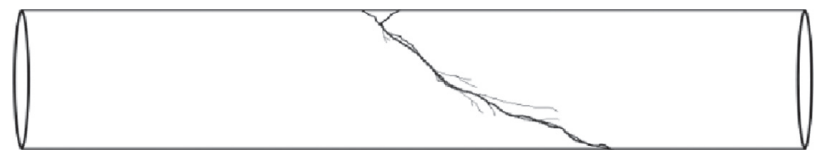

(c)

FIgURE 13: The fracture path profile of S-6. (a) Stage I. (b) Stage II. (c) Stage III.

\section{Conclusions}

The corrosion behavior and failure mechanism of bolt (cable) samples from a certain mine were analysed. The conclusions are as follows:

(1) The corrosion forms of the samples can be classified into (i) uniform corrosion and (ii) local pit corrosion (pitting). The main corrosion form of S-1 and S-2 samples is uniform corrosion, which has a short service time, but S-3, S-4, and S-5 samples with longer service lives experience different degrees of pit corrosion, and the number of corrosion spots on the bolt surface increases with service time.

(2) The corrosion amount of different parts of the bolt features the rule of anchor head $>$ anchor end $>$ free section. The bolt's corrosion amount increases with 
the service time, but the corrosion rate increases rapidly in the early stage and slows down in the later stage.

(3) The failure mechanism of sample S-6 is that it has been in the surrounding rock environment of $\mathrm{O}, \mathrm{Cl}$, and $\mathrm{S}$ for a long time, resulting in serious pitting corrosion and spalling of the surface material of the steel strand, which reduces the outer diameter of the rock cable and its bearing capacity and finally leads to the instantaneous SCC fracture of the S-6 sample.

\section{Data Availability}

The data used to support the findings of this study are available from the corresponding author upon request.

\section{Conflicts of Interest}

The authors declare that they have no conflicts of interest.

\section{Acknowledgments}

This research was supported by the Langfang Key Technology Research and Development Program of China (Grant no. 2020013039), the Special Fund of Basic Research and Operating of North China Institute of Science and Technology (Grant no. 3142020001), and the State Scholarship Fund of China, the National Natural Science Foundation of China (Grant no. 51804119).

\section{References}

[1] D. Vander, S. Saydam, C. Hangan et al., "Back-calculation of failure stress of rockbolts affected by Stress Corrosion Cracking in underground coal mines," International Journal of Rock Mechanics and Mining Sciences, vol. 310, no. 100, 2017.

[2] D. Hu et al., Application of Anchorage Technology on Geotechnical Engineering, China Building Industry Press, Beijing, China, 1987.

[3] J. Zhang, L. Han, B. Z. Zhu, and H. H. Zeng, "The problems related to the anchorage engineering for side slop and their effects," Journal of Railway Engineering Society, vol. 1, pp. 7-31, 2009.

[4] H. P. Kang and J. H. Wang, "J Lin, "Study and applications of roadway support techniques for coal mines," Journal of China Coal Society, vol. 35, no. 11, pp. 1809-1814, 2010.

[5] C. Zhang, F. Wang, and Q. Bai, "Underground space utilization of coalmines in China: a review of underground water reservoir construction," Tunnelling and Underground Space Technology, vol. 107, 2021.

[6] C. Zhang, Q. Bai, and Y. Chen, "Using stress path-dependent permeability law to evaluate permeability enhancement and coalbed methane flow in protected coal seam: a case study," Geomechanics and Geophysics for Geo-Energy and Geo-Resources, vol. 6, no. 3, pp. 1-25, 2020.

[7] X. M. Zeng, Z. Y. Chen, J. T. Wang, and Y. H. Du, "Research on safety and durability of bolt and cable-supported structures," Chinese Journal of Rock Mechanics and Engineering, vol. 23, no. 13, pp. 2235-2242, 2004.

[8] M. Zhang, Safety and Durability Analysis of china Railway Tunnel Structure," Engineering Technology BBS: Civil
Structural Engineering the Security and the Durability, Tsinghua University Press, Beijing, China, 2001.

[9] X. L. Liu, Fundamental Research of Structural Engineering Durability," Engineering Technology BBS: Civil Structural Engineering the Security and the Durability, Tsinghua University Press, Beijing, China, 2001.

[10] C. Dhanesh and D. Jack, "Sub-surface corrosion research on rock bolt system," perforated SS sheets and steel sets for the Yucca mountain repository quarterly technical report," Las Vegas: The University of Nevada, vol. 12, pp. 10-15, 2007.

[11] A. A. G. Erwin, "Environmental influence on the stress corrosion cracking of rock bolts," Engineering Failure Analysis, vol. 10, pp. 521-558, 2003.

[12] J. Zheng, H. H. Zeng, and B. Z. Zhu, "Test study of influence of erosion on mechanical behavior of anchor," Chinese Journal of Rock Mechanics and Engineering, vol. 29, no. 12, pp. 24692474, 2010.

[13] J. Zhao, W. Z. Ji, X. M. Zeng et al., "Experimental study on durableness of anchor with stress corrosion," Chinese Journal of Rock Mechanics and Engineering, vol. 1, pp. 3427-3431, 2007.

[14] Y. Y. Li, Study on Long Term Stability of Geotechnical Prestressed Anchor System, Beijing Jiaotong University, Beijing, China, 2008.

[15] H. S. Li, The Corrosion Regularity and Durability of Prestressed Anchor, Hebei University of Engineering, Handan, China, 2017.

[16] H. H. Zeng, B. Z. Zhu, and Z. H. Gao, "Experimental study on strength characteristics of cable under powerful corrosion," Journal of Water Resources and Architectural Engineering, vol. 9, no. 2, pp. 48-52, 2011.

[17] S. F. Zhang, X. Q. Chen, B. Han, and H. Qi, "Study on corrosion damage evolution mechanism of geotechnical prestressed anchor cable," Journal of Shandong Jianzhu University, vol. 33, no. 6, pp. 1-6+14, 2018.

[18] N. Aziz, P. Craig, J. Nemcik et al., "Rock bolt corrosion-an experimental study," Mining Technology, vol. 123, no. 2, 2014.

[19] S. Wu, H. Chen, P. Craig et al., "An experimental framework for simulating stress corrosion cracking in cable bolts," Tunnelling and Underground Space Technology, vol. 76, 2018.

[20] E. Proverbio and P. Longo, "Failure mechanisms of high strength steels in bicarbonate solutions under anodic polarization," Corrosion Science, vol. 45, no. 9, pp. 2017-2030, 2003.

[21] J. Toribio, B. González, and J. C. Matos, "Fatigue and fracture paths in cold drawn pearlitic steel," Engineering Fracture Mechanics, vol. 77, no. 11, pp. 2024-2032, 2010.

[22] M. Perrin, L. Gaillet, C. Tessier, and H. Idrissi, "Hydrogen embrittlement of prestressing cables," Corrosion Science, vol. 52, no. 6, pp. 1915-1926, 2010. 